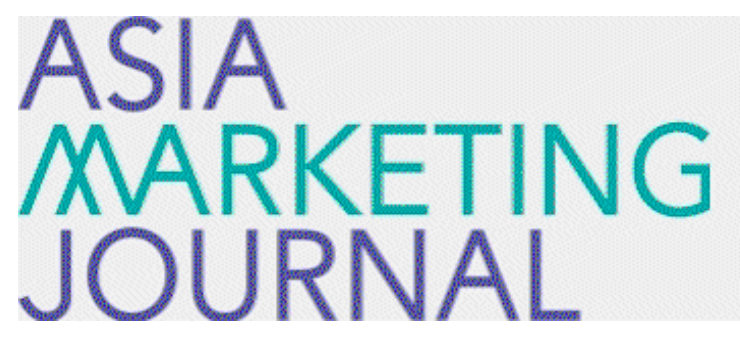

ASIA MARKETING JOURNAL

Volume 3 | Issue 2

Article 1

6-30-2001

\title{
LISREL 적용상의 유의사항과 문제점
}

현철 조

재원 유

Follow this and additional works at: https://amj.kma.re.kr/journal

Part of the Marketing Commons

\section{Recommended Citation}

조, 현철 and 유, 재원 (2001) "LISREL 적룡상의 유의 사항과 문 제점," Asia Marketing Journal: Vol. 3 : Iss. 2, Article 1.

Available at: https://doi.org/10.53728/2765-6500.1060

This Article is brought to you for free and open access by Asia Marketing Journal. It has been accepted for inclusion in Asia Marketing Journal by an authorized editor of Asia Marketing Journal. 


\title{
LISREL 적용상의 유의사항과 문제점
}

\section{A Study on Problems and Suggestions of Using LISREL}

\author{
조현철 (한양대학교 디지털경영학부 교수) \\ chohyunc @enanyang. ac. kr
}

유재원(한양대학교 경영학과 박사과정)

yj w@i gi t al . re. kr

\begin{abstract}
본 연구는 리즈렐을 이용한 자료 분석에서 실제적으로 발생할 수 있는 문제점과 유의해야 할 사항을 실증자료를 이용하여 고찰하기 위한 것이다. 분석자료는 수도권에 소재하고 있는 보험판매영업소에서 판매활동을 하고 있는 328 명의 보험판매원의 조직시민 행동 (organizational citizenship behaviors, $\mathrm{OCB}$ )에 영향을 미치는 선행변수를 파악하기 위해 수집된 자료를 이용하였다. LISREL 적용상의 유의사항으로는 구성 개념과 지표간의 관계 및 구성 개념간의 관계, 좋은 참조변수 지정의 중요성, $\chi^{2}$ 검정 적용상의 유의사항, 식별되지 않은 모델과 관련한 유의사항, 초기설정치의 제공과 수용하기 어려운 해와 관련한 유의사항, 모델 탐색시의 유의사항, 공분산행렬로 분석하지 않고 상관 행렬로 분석하는 경우의 문제점, 표본크기 확인과 분석에 선택된 변수 지정의 중요성, 전반적인 적합도에 의한 모델의 검정, 결과 해석과 보고시의 유의사항을 다루고 있다. 이어서, LISREL에 있어서의 모수 유의성 검정상의 문제점에 대해 고찰하고 있으며, LISREL의 유용성과 한계점에 대해서도 다루고 있다.
\end{abstract}

\footnotetext{
* 논문접수: 01. 10 게재확정: 01. 11

이 논문은 1999년도 교내 학술조성비에 의해 연구되었음.
} 


\section{1. 서 론}

연구자들은 대량의 정보 속에 내재된 공통의 원인을 규명하기 위해서 또는 원인과 결과간의 인과관계를 규명하기 위하여 구조방정식모델을 포괄적으로 다룰 수 있는 통계프로그램인 LI SREL을 널리 사용하고 있으며, 이는 교육학, 심리학, 사회심리학, 사회학, 경영학, 경제학, 생물학, 의학 등에 걸친 여러 분야에서 널리 적용되어 오고 있다. 하지만 연구자가 LI SREL을 이용하여 분석을 할 경우에 발생할 수 있는 문제점에 관하여 포괄적으로 언급한 기존의 연구는 찾아보기 어렵다고 본다.

따라서 본 논문에서는 수집한 자료를 이용해 구조방정식 모델(structural equat $i$ on modeling), 특히 LISREL을 이용하여 인과관계 분석을 실시할 경우 발생할 수 있는 주요 문제점과 유의사항에 대해 e- mai 로 질문 받은 사항을 참고하여 고찰하고자 한다.

\section{LISREL 적용상의 유의 사항}

분석 사례로 이용될 자료는 수도권에 소재하고 있는 보험판매영업소에서 판매활동을 하 고 있는 328 명의 보험판매원의 조직시민행동(organizational citizenship behaviors, OCB)에 영향을 미치는 선행변수를 고찰하기 위해 수집된 자료이다(조 유 2000). 적용된 인과관계 모델은 [그림 1]과 같다.

<그림 1> 인적판매상황에서 조직시민행동의 선행변수에 관한 모델

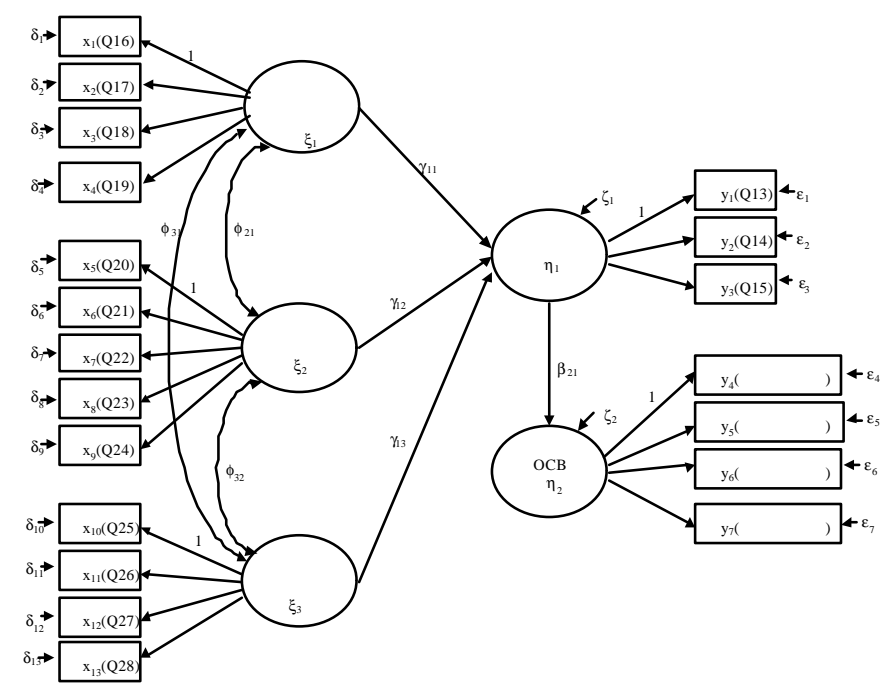




\section{1 구성개념과 지표간의 관계 및 구성개념간의 관계}

일반적으로 이론(theory)이나 연구가설(research hypothesis)은 추상적인 개념간의 관계로 기술되어 있다. 이러한 추상적 개념(concept)에 대응하여 공분산 구조 분석 (covari ance structure anal ysi s) 또는 구조방정식모델( structural equati on model ing) 에서는 구성개념(構成概念, construct)이라는 용어를 사용하며, 이 구성개념을 측정하기 위한 변수는 관측변수( observed variables) 또는 지표(indi cators)라 부르고 있다.

\subsection{1 구성개념과 지표간의 관계}

우선, 측정모델(measurement model) 을 구성하는 각 구성개념과 이의 관측변수(지표) 간의 관계에 대해 언급하고자 하는데, 측정모델을 구성하기 위해서는 해당 관측변수들의 배후에 잠재해 있는 공통의 원인을 규명해야 한다. 이 공통 원인(common cause)이 구성 개념 (잠재변수)에 해당하며 확인적 요인분석(confirmat ory factor analysis)에 있어서의 요인이다. [그림 1] 에서는 개인과 조직간의 적합성 $\left(\xi_{1}\right)$, 리더의 지원( $\left.\xi_{2}\right)$, 보상할당의 공정성 $\left(\xi_{3}\right)$, 직무만족 $\left(\eta_{1}\right.$ ) 및 $\mathrm{OCB}$ (조직시민행동, $\eta_{2}$ )라는 5 개의 구성개념이 제시되어 있다. 달리 표현하면, 3 개의 외생잠재변수(exogenous I atent variables) 인 $\xi_{1} \sim \xi_{3}$ 및 2 개의 내생잠재변수(endogenous latent variables)인 $\eta_{1}$ 과 $\eta_{2}$ 등 5 개의 잠재변수(구성개념)로 구성되어 있다. 여기서, 개인과 조직간의 적합성( $\xi_{\text {l }}$ )은 관측변수(observed variables) 인 $\mathrm{x}_{1} \sim \mathrm{x}_{4}$ 의 공통원인에 해당하며, 리더의 지원( $\xi_{2}$ )은 관측변수( observed vari ables) 인 $x_{5} \sim x_{9}$ 의 공통원인에 해당하고, 보상할당의 공정성( $\xi_{3}$ ) 은 관측변수( observed variables) 인 $x_{10} \sim x_{13}$ 의 공통원인에 해당한다. 한편, 직무만족( $\eta_{1}$ ) 은 $\mathrm{y}_{1} \sim \mathrm{y}_{3}$ 의 공통원인에 해당하며, $\operatorname{OCB}\left(\eta_{2}\right)$ 는 $\mathrm{y}_{4} \sim \mathrm{y}_{7}$ 의 공통원인에 해당한다. 예컨대, 공통원인에 해당하는 $\mathrm{OCB}\left(\eta_{2}\right)$ 의 수준이 높은 사람은 정당한 행동 $\left(\mathrm{y}_{4}\right)$ 의 수준도, 공익적 행동 $\left(\mathrm{y}_{5}\right)$ 의 수준도, 양심적 행동 $\left(\mathrm{y}_{6}\right)$ 의 수준도, 그리고 이타적 행동 $\left(\mathrm{y}_{7}\right)$ 의 수준도 모두 높게 나타나게 된다는 것을 의미한다. 또한 이것은 각 구성개념(잠재변수)과 이의 지표(관측변수) 간의 관계를 나타내는 경로계수가 양의 값을 갖도록 자료가 정리되어 있어야 하며, 이들 경로계수가 유의함으로써 수렴타당성이 인정될 수 있어야 한다는 것을 의미하게 된다. 즉, $\Lambda_{x}$ 와 $\Lambda_{y}$ 의 모든 원소는 유의한 양의 값으로 추정될 수 있도록 입력자료가 정리되어 있어야 하는 것이다. 따라서, 우선, 어떤 구성개념을 측정하기 위한 지표 가운데서 다른 지표들과는 역으로 질문한 항목이 있는 경우에는 역전시킨 점수(reversed score)를 사용함으로써 양의 부호가 추정될 수 있도록 해야 하며, 이들 지표의 신뢰성을 검토해야 한다. 양의 부호로 추정되도록 자료가 정리되어 있지 않으면, 이어서 고찰될 구성개념간의 관계를 추정하는 데에도 결정적인 영향을 미치게 된다( 예컨대, 임 pp. 3467 및 p. 357). 각 구성개념과 지표간의 '인과계수는 유의한 양 $(+)$ 의 값이 기대된다'는 점을 확인하는 하나의 방법은 첫째, 지표간의 상관행렬에서 해당 지표간의 부호가 양인지를 검사하는 것이다. 둘째, LI SREL 로 모델을 추정하기 이전에, 다른 방법(예컨대, Cronbach's a 혹은 Al pha if item del et ed 항목)으로 계산된 각 지표의 신뢰성을 검토하여 신뢰성에 문제가 있을 것으로 
예상되는 지표를 확인하여 모델 추정 후에 얻어지는 신뢰성계수(SMC)와 비교해 검토하는 것이다.

2.1.2 구성 개념간의 관계

이어서, 잠재 변수간의 영향력의 관계를 명시할 구조모델(structural model)을 구성하기 위해서는 구성 개념간의 인과관계(casual relationship)를 규명해야 한다. 인과관계를 규명하기 위해서는 구성 개념간의 인과관계에 대한 연구가설(research hypothesi s)이 존재해야 한다. 그리고 이 연구가설은 충분한 문헌고찰이나 추론을 통해 이론과 실질적 지식에 입각하여 설정된 것으로서 관련 구성개념은 측정 가능해야 한다. 즉, 이론적 추론과 광범위한 관찰에 근거하여 구성 개념간의 관계에 대해 설정한 연구가설이 인과관계의 규명을 위해서는 필요한 것이다. 연구자가 검정하고자 하는 인과관계에 관한 연구가설은 구조모델과 직접적인 대응관계가 성립한다. 따라서, 구조방정식모델의 경로도(path di agram) 에서 구성 개념간의 직선화살표 $(\rightarrow)$ 를 포함하고 있는 경로는 연구가설의 한 표현 방식에 해당한다. 잠재 변수간의 영향력의 방향을 명시하고 있기 때문이다.

그러면, 여기서 [그림 1]에 제시된 모델을 바탕으로 구성 개념간의 관계에 대해 살펴보기로 하자. 설명의 편의상 경로도가 먼저 제시되어 있으나 실제로 인과관계모델을 구성해 가는 상황에서는 구성 개념간의 연구가설이 설정된 다음, 이들 연구가설을 바탕으로 인과관계에 관한 경로도를 작성할 수 있게 된다. 문헌고찰, 탐색적 연구, 관련 지표간의 상관분석, 관찰 등을 통해 개인과 조직간의 적합성 $\left(\xi_{1}\right)$, 리더의 지원 $\left(\xi_{2}\right)$ 및 보상할당의 공정성 $\left(\xi_{3}\right)$ 에 있어서 이들이 높다고 인식한 사람은 직무만족 $\left(\eta_{1}\right)$ 이 높은 수준으로 나타날 것이며, 직무만족 $\left(\eta_{1}\right)$ 이 높은 판매원은 조직시민행동 $\left(\eta_{2}\right)$ 도 높게 나타날 것이라고 추측할 수 있을 것이다. 따라서, 다음과 같은 연구가설을 설정할 수 있다.

연구가설1 $(\mathrm{RH} 1)$ : 개인과 조직간의 적합성은 직무만족에 정의 영향을 미친다.

연구가설2 (RH2): 리더의 지원은 직무만족에 정의 영향을 미친다.

연구가설3 (RH3): 보상할당의 공정성은 직무만족에 정의 영향을 미친다.

연구가설4 ( $\mathrm{RH} 4)$ : 직무만족은 조직시민행동에 정의 영향을 미친다 (즉, 직무만족이 높은 판매원일수록 조직시민행동을 강하게 보일 것이다).

여기서, 연구자가 유의할 점은 연구가설에서 각 구성 개념간에 가정된 관계와 그 부호가 바르게 추정될 수 있도록 입력자료가 정리되어 있어야 한다는 점이다. 경험 있는 연구자도 이 점에 대한 검토를 간과하는 경우가 있다. 자료가 제대로 정리되어 있지 않으면 연구가설에서 가정하고 있는 관계와는 반대의 부호가 추정될 수 있기 때문이다. 드물게, 자료가 연구가설에서 의도하는 대로 정리되어 있지만 일부의 모수에서 역의 부호로 추정되는 경우, 이에 대한 설명을 제대로 하기 위해서는, 관련 이론과 지식의 관점에서 면밀한 검토 작업을 필요로 한다. 예컨대, 어떤 구성개념(예, $\eta_{\mathrm{l}}$ )에 대해 복수의 구성개념(예, $\xi_{1}, \xi_{2}$ 및 $\left.\xi_{3}\right)$ 이 동시에 영향을 미치고 있는 경우 이들 경로계수는 구성 개념간의 단순회귀계수가 아니라 편회귀계수에 해당하므로 해석에 주의를 요한다. 독립변수를 하나씩 적용하여 얻은 단순회귀계수와 독립변수를 동시에 적용하여 분석하였을 
때 얻어지는 편회귀계수 간에는 서로 부호가 일치하지 않는 결과가 일부의 모수에서 얻어질 수도 있기 때문이다.

이어서, 다수의 구성개념이 어떤 구성개념에 영향을 미치고 있는 것으로 가정하고 있는 모델에 있어서 원인변수에 해당하는 구성 개념들 간에 높은 상관이 존재하는 경우, 즉 독립변수에 해당하는 다수의 구성 개념들 간에 다중공선성(multicolli nearity)이 존재하는 경우 모든 독립변수가 종속변수에 유의한 영향을 미치지 않는다는 $t$ 검정 결과가 얻어지지만, 종속변수에 대한 설명력에 해당하는 결정계수(LISREL 출력에서 구조방정식에 대한 SMC에 해당) 는 상당히 높게 나오는 결과를 얻게 되는 경우가 있다( Makri daki s and Wheel wri ght 1978; Neter, WAsserman, and kutner 1985). [ 그림 1]을 예로 설명하면, 3 개의 외생변수 $\xi_{1}$, $\xi_{2}$ 및 $\xi_{3}$ 이 $\eta_{1}$ 에 영향을 미치는 것으로 보고 있는데 이들 외생변수 간에 상관이 높다면 다중공선성으로 인한 문제가 발생하게 된다. 일반적으로 독립변수간의 단순상관계수가 0.7 이상이면 다중공선성으로 인한 문제가 발생하는 것으로 지적되고 있다(Makridakis and Wheel wright 1978 p. 210). 이러한 경우 몇 개의 부분 모델로 수정하는 조치를 취하거나 모델을 새로 구성해야 할 경우도 있다. 사회과학 분야의 연구에서 많은 수의 외생변수를 도입하게 되면, 외생변수(구성개념)들 간에 상관이 높은 경우가 흔히 있을 수 있으므로 반드시 다중공선성으로 인한 문제점을 검토해야 할 필요가 있다. LI SREL 에서 구성 개념간의 상관을 검토하기 위해서는 출력에서 ' CORRELATI ON NATRIX OF ETA AND KSI' 란을 이용하면 된다(제 II 절 10 항 참조).

\section{2 좋은 참조변수 지정의 중요성}

통상, 각 참조변수의 경로계수는 1 로 고정을 하게 되는데, 이는 각 잠재변수에 대해 측정단위를 부여하여 모델을 식별(identification)하기 위한 하나의 방법으로 각 잠재변수의 지표 가운데서 하나씩 선택하여 경로계수를 1 로 고정시킨다는 의미이다. 편의상 첫 번째 지표로 향하는 경로계수를 1로 고정시키고 있으나 더 좋은 참조 변수가 있다면 그 변수로 향하는 경로계수를 고정시켜야 한다(조, 1999 p. 63). 이와 같이 참조변수의 지정은 모델을 식별하는데 매우 중요한 의미를 가지고 있지만 지표에 대한 상세한 고찰 없이 첫 번째 지표로 향하는 경로계수에 1의 값을 부여하여 고정시키는 경우가 일반적이다. 하지만 참조변수의 잘못된 지정으로 인해 모델을 추정한 결과에서 나타나는 영향은 매우 크다. 예를 들어 신뢰성이 낮은 지표를 참조변수로 지정하였을 때 나타나는 결과와 신뢰성이 높은 지표를 참조변수로 지정할 경우에 나타나는 결과에 대하여 고찰하기로 한다.

다음 [ 그림 2] 는 참조변수를 달리 지정한 경우의 영향을 고찰하기 위해 제시한 것으로, $\mathrm{OCB}\left(\eta_{2}\right)$ 의 참조변수를 신뢰성계수가 낮은 $\mathrm{y}_{4}$ 로 지정한 경우와 신뢰성계수가 높은 $\mathrm{y}_{5}$ 로 지정한 경우에 얻어지는 결과를 비교하기 위해 도시한 것이다. 


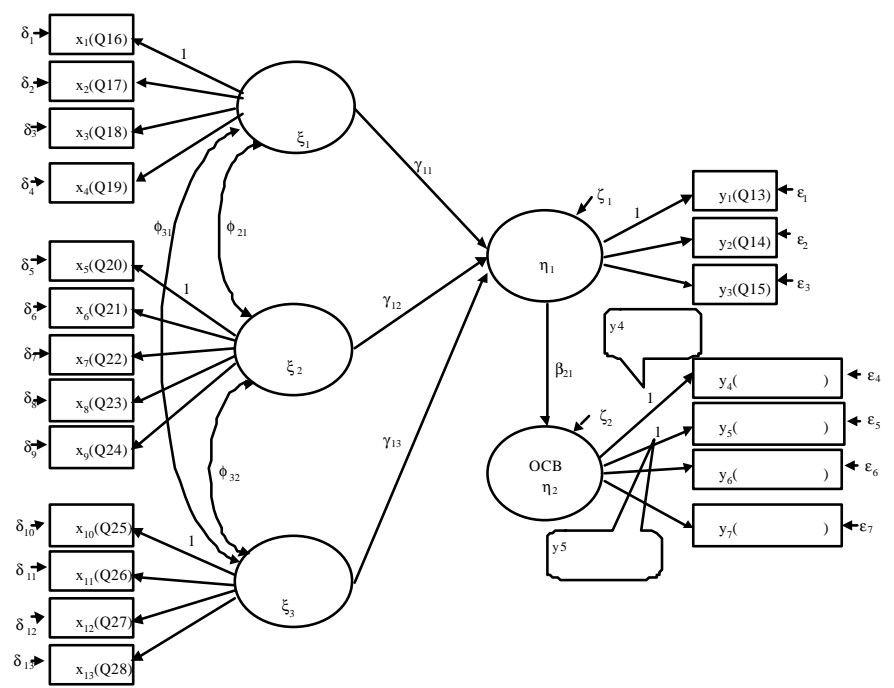

우선, 사전에 계산된 신뢰성계수인 Cronbach's a 와 LI SREL에 의해 사후에 추정된 신뢰성계수인 SMC(squared mul ti ple correl ation)를 요약하면 다음 <표 1>과 같다.

<표 1>에서 나타난 것처럼 신뢰성 계수인 Cronbach' a 와 다중상관의 제곱(SMC)이 낮은 정당한 행동 $\left(\mathrm{y}_{4}\right)$ 을 첫 번째 지표라는 이유로 참조 변수로 지정한 경우 나타난 결과와, 신뢰성이 양호한 공익적 행동 $\left(\mathrm{y}_{5}\right)$ 을 참조변수로 지정한 경우 나타난 결과를 <표 2>에서 살펴보면 다음과 같은 차이가 발생하고 있다는 것을 알 수 있다. 즉, $\mathrm{y}_{4}$ 를 참조변수로 지정하기 위해 $\lambda_{42}^{(y)}$ 를 1.0 으로 고정하였을 때 조직시민행동의 지표로 향하는 경로계수 중에서 $\lambda_{52}^{(y)}, \lambda_{62}^{(y)}$ 및 $\lambda_{72}^{(y)}$ 가 모두 유의하지 않은 것으로 나타났으며 부호도 음의 값이 얻어졌다. 세 외생변수 $\xi_{1} \sim \xi_{3}$ 으로부터 $\eta_{1}$ 로 향하는 경로계수 $\gamma_{11}, \gamma_{12}$ 및 $\gamma_{13}$ 이 모두 유의하지 않은 것으로 나타났다.

<표 1> 구성개념별 지표에 대한 신뢰성계수: SMC와 Cronbach's a

\begin{tabular}{|c|c|c|c|c|}
\hline 구성개념 & 구성요소 & 항목수 & \begin{tabular}{|l} 
다중상관의 \\
제곱( SMC)
\end{tabular} & Cronbach's a \\
\hline \multirow{4}{*}{ 조직시민행동 } & 정당한 행동 $\left(\mathrm{y}_{4}\right)$ & 3 개 & $0.002^{a}$ & $0.4874^{b}$ \\
\hline & 공익적 행동 $\left(\mathrm{y}_{5}\right)$ & 3 개 & $0.455^{\mathrm{a}}$ & $0.7013^{b}$ \\
\hline & 양심적 행동 $\left(\mathrm{y}_{6}\right)$ & 3 개 & $0.584^{a}$ & $0.7854^{b}$ \\
\hline & 이타적 행동 $\left(\mathrm{y}_{7}\right)$ & 3 개 & $0.522^{a}$ & $0.8521^{b}$ \\
\hline \multirow{3}{*}{ 직무만족 } & $\left(y_{1}\right)$ & \multirow{3}{*}{3 개 } & 0.759 & \multirow{3}{*}{0.8874} \\
\hline & $\left(y_{2}\right)$ & & 0.642 & \\
\hline & $\left(y_{3}\right)$ & & 0.784 & \\
\hline
\end{tabular}




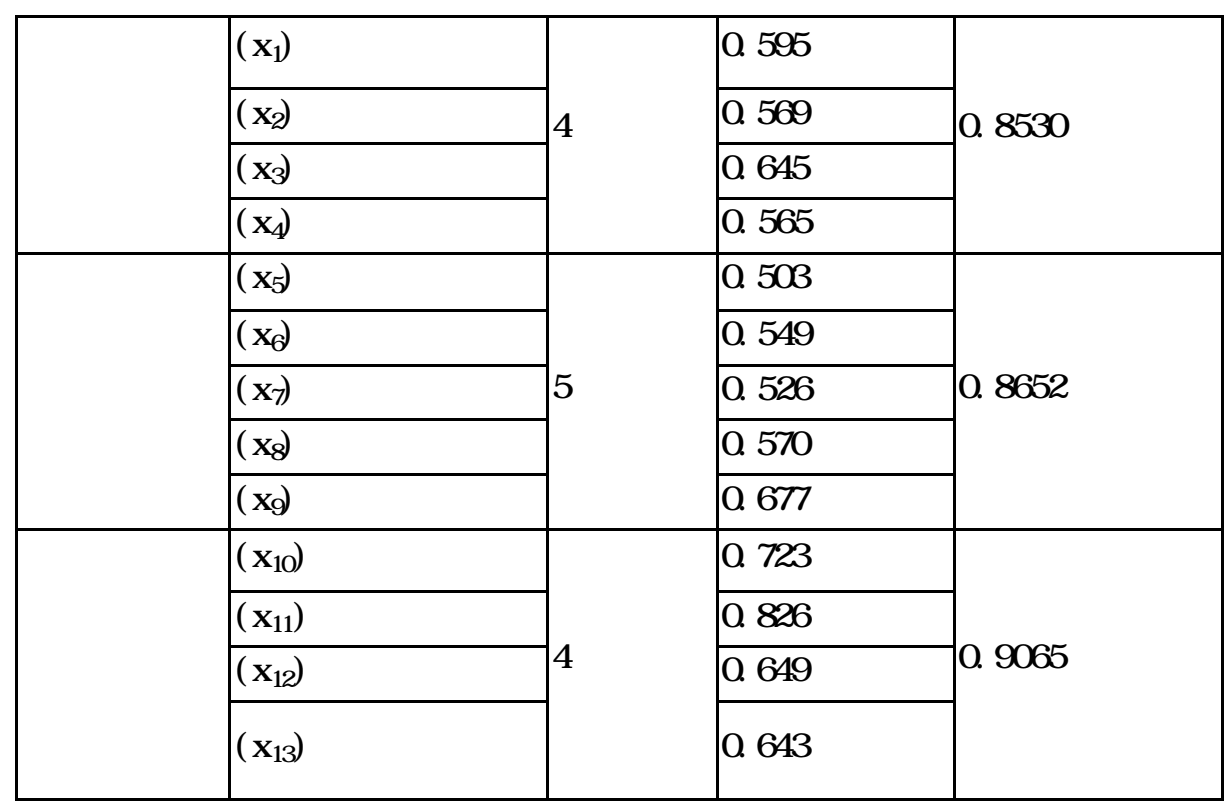

[ 주] 는 각 지표를 평균한 것으로 확인적 요인분석에 의해 계산된 것이며, ${ }^{b}$ 는 각 지표를 그대로 적용하여 계산된 것이다.

또한, 직무만족과 조직시민행동간의 경로계수 $\beta_{21}$ 의 추정치는 - 0.167 ( $\mathrm{t}$ 값=0.530)로 나타나 유의수준 $\mathrm{a}=0.10$ 에서 유의하지 않은 것으로 나타났다. 뿐만 아니라, $\mathrm{y}_{4}$ 에 대한 신뢰성계수인 $\mathrm{SMC}$ 는 0.002 로, $\mathrm{y}_{5}$ 에 대한 $\mathrm{SMC}$ 는 0.046으로, $\mathrm{y}_{6}$ 에 대한 $\mathrm{SMC}$ 는 0.060으로, $\mathrm{y}_{7}$ 에 대한 $\mathrm{SMC}$ 는 0.529 로 나타나 $\mathrm{y}_{7}$ 을 제외한 나머지 지표는 신뢰성이 $\mathrm{O}$ 에 가깝게 추정되어 신뢰할 수 없는 지표라는 결과가 얻어졌다. 이 경우 문제점을 발견하기 위한 한 방법은 각 잠재변수의 결정계수에 해당하는 $\mathrm{SMC}$ 가 어느 정도인지를 검토하는 것이다. $\eta_{\mathrm{l}}$ 의 결정계수인 $\mathrm{SMC}$ 는 0.340 으로, 그리고 $\eta_{2}$ 의 결정계수인 $\mathrm{SMC}$ 는 0.046 으로 추정되었으므로 모델 명시(model specification)에 문제점이 있을 것이라는 시사를 얻게 되었다.

따라서, 지표의 신뢰성을 검토하게 되었으며, 신뢰성이 낮은 $\mathrm{y}_{4}$ 대신에 신뢰성이 양호한 $\mathrm{y}_{5}$ 를 참조변수로 지정하기 위해 $\lambda_{52}^{(y)}$ 를 1.0 으로 고정하여 추정하는 조치를 취할 수 있게 되었다. 그 결과 조직시민행동의 지표로 향하는 경로계수 중에서는 $\mathrm{y}_{4}$ 로 향하는 $\lambda_{42}^{(y)}\left(\mathrm{t}\right.$ 값=0.909) 만 유의하지 않은 것으로 나타났으며, $\mathrm{y}_{6}$ 으로 향하는 $\lambda_{62}^{(y)}(\mathrm{t}$ 값=10. 452) 와 $\mathrm{y}_{7}$ 로 향하는 $\lambda_{72}^{(y)}$ ( $\mathrm{t}$ 값=10. 232) 는 유의한 것으로 나타났다. 또한 이들 추정치의 부호도 모두 양의 값으로 얻어졌다. 직무만족과 조직시민행동간의 경로계수 $\beta_{21}$ 의 추정치도 양의 값인 1. 201( $\mathrm{t}$ 값=8.526)로 유의수준 $a=0.01$ 에서 유의하다는 결과가 얻어졌다. 또한, $y_{4}$ 를 참조변수로 지정하여 추정한 결과에서는 모두 유의하지 않은 것으로 나타났던 $\gamma_{11}, \gamma_{12}$ 및 $\gamma_{13}$ 이 $y_{5}$ 를 참조변수로 지정하여 추정하자 $\gamma_{11}$ ( $\mathrm{t}$ 값=7.162) 과 $\gamma_{12}$ ( $\mathrm{t}$ 값=4.785) 는 유의수준 $a=0.01$ 에서 유의하다는 결과가 얻어졌으며, $\gamma_{13}$ ( $\mathrm{t}$ 값=1.635) 은 유의수준 $a=0.05$ 에서 유의하지는 않지만(유의: 우측검정을 적용하고 있음), 임계치 1.645 에 가까운 추정치가 얻어졌다. 
이들 추정치의 부호도 연구가설에서 의도하는 방향으로 양의 부호가 얻어졌다

<표 2> 참조변수를 $\mathrm{y}_{4}$ 와 $\mathrm{y}_{5}$ 로 지정한 경우의 결과 비교표

\begin{tabular}{|c|c|c|c|c|c|c|c|}
\hline \multicolumn{4}{|c|}{$\mathrm{y}_{4}$ 를 참조변수로 지정 } & \multicolumn{4}{|c|}{$\mathrm{y}_{5}$ 를 참조변수로 지정 } \\
\hline 모수 & 추정치 & (표준오차) & $\mathrm{t}$ 값 & 모수 & 추정치 & (표준오차) & $\mathrm{t}$ 값 \\
\hline$\lambda_{42}^{(y)}$ & 1. 000 & & & $\lambda_{42}^{(y)}$ & 0.069 & $(0.076)$ & 0.909 \\
\hline$\lambda_{52}^{(y)}$ & 8. 741 & ( 16. 050) & -0.545 & $\lambda_{52}^{(y)}$ & 1. 000 & & \\
\hline$\lambda_{62}^{(y)}$ & 10. 497 & (19. 202) & -0.547 & $\lambda_{62}^{(y)}$ & 1. 163 & 0.111 & 10. 452 \\
\hline$\lambda_{72}^{(y)}$ & 8.653 & ( 15. 950) & -0.542 & $\lambda_{72}^{(y)}$ & 1. 060 & 0.104 & 10. 232 \\
\hline$\gamma_{11}$ & 0.442 & $(0.617)$ & 0.716 & $\gamma_{11}$ & 0.746 & ( 0.104$)$ & 7. 162 \\
\hline$\gamma_{12}$ & 0.558 & (0.493) & 1. 131 & $\gamma_{12}$ & 0.334 & $(0.070)$ & 4. 785 \\
\hline$\gamma_{13}$ & 0.087 & $(0.549)$ & 0.158 & $\gamma_{13}$ & 0. 151 & (0.092) & 1. 636 \\
\hline$\beta_{21}$ & -0.167 & (0.315) & -0.530 & $\beta_{21}$ & 1. 201 & 0.141 & 8. 526 \\
\hline$\phi_{44}^{(\varepsilon)}$ & 48.036 & 3. 761 & 12. 772 & $\phi_{44}^{(\varepsilon)}$ & 8. 186 & 0.641 & 12. 776 \\
\hline$\phi_{55}^{(\varepsilon)}$ & 121.879 & 10. 053 & 12. 124 & $\phi_{55}^{(\varepsilon)}$ & 6. 186 & 0.643 & 9.624 \\
\hline$\phi_{66}^{(\varepsilon)}$ & 134. 384 & 11. 354 & 11.836 & $\phi_{66}^{(\varepsilon)}$ & 5. 475 & 0.691 & 7. 925 \\
\hline$\phi_{77}^{(\varepsilon)}$ & 5. 182 & 2. 619 & 1.979 & $\phi_{77}^{(\varepsilon)}$ & 5. 767 & 0.646 & 8. 932 \\
\hline SMC & & & & SMC & & & \\
\hline $\mathrm{y}_{4}$ & 0.002 & & & $y_{4}$ & 0.003 & & \\
\hline$y_{5}$ & 0.046 & & & $\mathrm{y}_{5}$ & 0.473 & & \\
\hline $\mathrm{y}_{6}$ & 0.060 & & & $\mathrm{y}_{6}$ & 0.579 & & \\
\hline$y_{7}$ & 0.529 & & & $y_{7}$ & 0.520 & & \\
\hline
\end{tabular}

위의 결과에서 볼 수 있는 바와 같이 신뢰성이 낮은 지표를 참조변수로 지정할 경우에는 유의한 경로에 대해 유의하지 않다는 검정 결과가 얻어질 수 있으며, 또한 경로계수의 부호도 연구가설에서 의도하는 방향과 역의 부호로 추정될 수 있으며, 각 지표의 신뢰성계수에 해당하는 SMC도 정확하게 추정되지 않는 치명적인 결과가 발생하는 것으로 나타났다. 신뢰성계수가 양호한 지표를 참조변수로 지정하는 것이 중요하다는 점을 시사하고 있다고 하겠다. 따라서 인과관계모델을 분석하고자 하는 경우에는, 우선적으로, 지표가 다수일 때에는 모델설계 단계에서 2단계 접근법( two-step approach) 을 적용하여 우수한 지표를 선별한 다음에 모델을 설계하도록 권장되고 있다(예컨대, Ander son and Gerbi ng 1988; Janæs, Mll ai k, and Brett 1982; Mul ai k et al. 1989; Schumacker and Lomax 1996). 


\section{2. $3 \chi^{2}$ 검정 적용상의 유의사항}

LI SREL모델에 대한 $\chi^{2}$ 검정에 있어서의 $\chi^{2}$ 통계량은 명시(specification)된 모델의 적합도 함수가 갖는 최소값을 (N-1)배한 것이다. 여기서 $\mathrm{N}$ 은 표본크기이다 (Bollen, 1989; $J$ reskog \& S rbom 1988). 자유도에 비해 $\chi^{2}$ 값이 상대적으로 크다는 것은 제약이 부여되어 있는 모델이 자료에 제대로 부합되지 않는다는 것을 의미한다. 그런데 $\chi^{2}$ 통계량은 '모델이 모집단에 있어서 적합하다' 와 같은 복합가설(composi te hypothesi s) 을 검정하고자 하는 경우에는 다음 세 가지 요건을 충족시켜야 한다(J reskog \& S rbom, 1988) .

(1) 관측변수들은 다변량정규분포를 한다.

(2) 분석은 표본공분산행렬에 입각해 있다 (즉, 표준화된 상관행렬이 아님).

(3) 표본크기는 상당히 크다.

이들 세 요건 모두를 제대로 충족시키는 경우는 현실적으로 드물다. 따라서 $\chi^{2}$ 통계량을 검정통계량으로 간주하는 대신, 모델의 양호도 내지는 불량도의 척도로 간주해야 할 것이다. 이때, $\chi^{2}$ 통계량은 표본크기에 민감하게 반응한다는 점에 유의해야 한다. 대개 표본수가 200 이상으로 증가하면 $\chi^{2}$ 검정은 유의한 p값 (즉, p val ue<a)을 나타내는 경향이 있어 모델이 적절하다는 귀무가설이 기각되기 쉬우며, 반대로 표본수가 대개 100이하로 감소하면 유의하지 않은 P값 (즉, $\mathrm{p}$-val ue $\geq a$ ) 을 나타내는 경향이 있어 귀무가설이 기각되지 않기 쉽다(Schumacker and Lomax 1996, p. 125). 또한 $\chi^{2}$ 검정은 관측변수가 다변량 정규분포에서 벗어나는 경우에도 민감하게 반응한다. 따라서 표본크기(sample si ze)가 충분히 크고 검정 대상 모델에 대한 이론적 뒷받침이 상당히 있다면, $\chi^{2}$ 검정을 너무 엄격하게 적용하지 않도록 제안하고 있다(豊田, 1992; 조 1999). 즉, 참고하는데 그치라는 것이다.

$\chi^{2}$ 통계량을 적절히 이용하는 방법 가운데의 하나는 그 차이를 사용하는 것이다(Bollen, 1989 ; Hayduk, 1987 ; Long, 1983b). $\chi^{2}$ 차이에 의한 검정( $\chi^{2}$ difference test)은 내포(內包)된 모델(nested model)을 비교하는 데 사용될 수 있다. 만약 모델 $\mathrm{M}$ 이 모델 $\mathrm{M}$ 로부터 1개 또는 2개 이상의 모수를 제약하여 얻은 것일 경우, $\mathrm{M}$ 은 $\mathrm{M}$ 에 내포되었다고 한다. 가령 모델 $\mathrm{M}_{1}$ 의 $\chi^{2}$ 값을 $\chi_{1}^{2}$ 이라 하고 그 자유도를 $\mathrm{df}_{1}$ 이라 하자. 그리고 모델 $\mathrm{M}_{2}$ 의 $\chi^{2}$ 값을 $\chi_{2}^{2}$ 이라 하고 그 자유도를 $\mathrm{df}_{2}$ 라 하자. 대표본인 경우 $\chi^{2}$ 값의 차이인 $\chi^{2}=\chi_{1}^{2}$ - $\chi_{2}^{2}$ 는 자유도가 $\mathrm{df}=\mathrm{df}_{1}-\mathrm{df}_{2}$ 인 $\chi^{2}$ 분포를 따른다. 자유도에 비해 상대적으로 $\chi^{2}$ 값이 크면 모델 $\mathrm{M}$ 에 새로 부가된 제약조건이 기각되어야 한다는 것을 의미한다. 이 경우 $\chi_{1}^{2}$ (내포된 모델) $>\chi_{2}^{2}$ (기본 모델) 및 $\mathrm{df}_{1}$ (내포된 모델) $>\mathrm{df}_{2}$ (기본 모델) 의 관계가 성립한다. 또한, 모델의 어떤 모수의 값이 특정한 값이라는 가설을 검정하고자 하는 경우나, 복수표본 분석(mul ti-sample analysis)시에도 유용하게 사용될 수 있다. 예컨대, 두 변수(구성개념) 
간에 완벽한 상관이 존재하는 지를 검정함으로써 판별타당성의 검정에 적용될 수 있으며, 두 집단에서 해당 경로가 동일한지의 여부를 검정하고자 하는 경우에도 적용될 수 있다(Bol Ien, 1989; Hoyl e, 1995; Narsh and Grason, 1995).

\section{4. 식별을 가능하게 하기 위한 조치}

관측변수인 $\mathrm{y}$ 변수와 $\mathrm{x}$ 변수의 공분산행렬로 모델에 포함된 모든 모수(parameter)의 유일한 해가 구해지는 경우, 모델은 식별(identification)되었다고 한다. 모델의 모수 가운데서 하나라도 식별되지 않으면 모델은 식별되지 않은 것이 된다.

통상, 모델의 식별수준은 다음 세 가지로 구분된다(Hayduck 1987; Schumacker and Lomax 1996) .

첫째, 표본공분산행렬 S에서 식별에 필요한 정보가 불충분하여 하나 혹은 그 이상의 모수의 유일한 해가 구해지지 않는 경우 식별불능모델(not-identified or unidentified model ) 이라고 한다.

둘째, 표본공분산행렬 S에서 식별에 꼭 필요한 만큼의 정보만 있는 경우 한계식별모델 혹은 포화모델(just-identified or saturated model)이라고 부른다.

끝으로, 표본공분산행렬 S에서 식별에 필요한 이상으로 정보가 많이 있는 경우 과잉식별모델(over-identified model) 이라고 한다. 과잉식별모델의 경우에는 모수의 유일한 해를 구할 수 있는 방법이 한 가지 이상이 존재한다. 포화모델이거나 과잉식별모델의 경우에 한 해 모델이 식별되었다고 하며(Hayduck 1987, p. 143; Schumacker and Lomax 1996, p. 100), 포화모델은 자유도가 0이고 과잉식별모델은 자유도가 양의 값을 갖게 된다.

모델의 식별과 관련하여 식별되지 않은 모델을 식별시키기 위한 방법은 하나뿐이다. 분석목적과 자료의 특성을 훼손시키지 않는 범위 내에서 모수에 많은 제약을 부여하여 추정할 모수의 수를 줄여 가는 것이다. 꼭 필요하지 않은 경로를 제거하거나, 각 참조변수에 대해 1 의 값으로 고정시키거나, 오차항 간에 무상관 가정을 도입할 수 있으며, 필요에 따라 구성개념의 분산을 1 로 표준화시키거나, 등식제약(等式制約)을 부여하는 등의 제약을 부여하면 추정할 모수가 줄어들면서 식별 가능성이 생겨난다. 따라서, 모델의 식별에 어려움이 발생하는 경우에는 식별을 위한 간편한 전략은 가능하면 제약을 많이 부여한 간명한 모델에서 출발하여 이 모델이 식별되면 필요한 모수를 단계적으로 늘려가는 방법을 택해 보는 것이다(Hoyle, 1995). 다양한 모델의 식별 조건에 대한 상세한 정보는 Bol I en(1989) 의 연구에서 상세히 설명되고 있다.

\section{5 초기설정치 제공 및 수용하기 어려운 추정치에 대한 검토}

우선, 모델을 식별 가능하게 하기 위해 적절한 초기설정치(starting value)를 설정할 필요가 있는 경우가 발생한다. 특히, $\mathrm{MMM}$ 탱렬에 대해 확인적 요인분석을 적용하여 분석하는 경우가 대표적인 경우인데 추정할 모수에 대해 적절한 초기설정치를 제공하지 않으면 모델의 식별에 실패할 수 있다. $\mathrm{AD}$ (허용 가능성 검사)나 I T(최대 반복횟수)의 수치를 늘려야 할 경우도 발생한다.

둘째, 모델의 해가 일단 얻어졌으나 일부의 모수에서 납득하기 어려운 추정치들을 
발견하게 되는 경우가 있다. 구체적으로 언급하면 상관행렬로 전환된 $\Phi$ 의 비대각원소 가운데서 상관이 1.0을 초과하는 값으로 추정되어 나오기도 한다. 경우에 따라서는 관측변수의 다중상관계수의 제곱( $\mathrm{SMC})$ 도 1 보다 크게 나오거나 음의 값이 나오기도 한다. 이러한 경우 일단 모델 명시(model specification)에 문제가 있는 것은 아닌지 검토에 들어가야 한다.

\section{6 모델 탐색시의 유의사항}

LISREL 출력에서 구성개념과 구성개념간에 유의한 경로가 존재하는 것으로 나타났다고 할지라도 이론적 고찰이나 실질적 지식에 근거하지 않고 단순히 자료에 대한 분석을 통하여 얻은 결과를 인과적인 관계가 있는 것으로 해석하는 것은 위험하다는 점을 지적하고 자 한다. 따라서 이론과 실질적 지식에 입각하여 설정된 인과관계모델의 경우에 한해서만 인과관계의 검증이 정당화 될 수 있으며, 모델의 수정 또한 같은 근거에 입각하여 실시될 때 의미를 갖게 되는 것이다. 그러나 이는 탐색적 연구에 대한 LI SREL을 포함한 구조방정식 모델의 적용 가능성을 부정하고자 하는 것은 아니며, 인과관계 모델이나 연구가설을 탐색하기 위해 사용될 수는 있지만 인과관계의 확립으로 보아서는 안 된다는 점을 강조하려는 것이다(Freedman, 1986, Boll en, 1989; Mttal, 1993).

\section{7 공분산행렬로 분석하지 않고 상관행렬로 분석하는 경우의 문제점}

LI SREL 프로그램에 있어 입력자료(i nput data)의 형태는 원자료( raw data), 공분산행렬(covariance matrix) 또는 상관행렬(correl ati on matrix) 가운데 어느 것이라도 분석에 들어갈 수 있다. 원자료로부터는 공분산행렬과 상관행렬 등 가능한 모든 행렬의 계산이 가능하다. 상관행렬과 표준편차가 입력자료로 주어지면 공분산행렬의 계산도 가능해진다. 그러나 가능하면 분석될 행렬(matrix to be analyzed)은 상관행렬보다는 공분산행렬로 하도록 권장되고 있다. 이는 측정단위가 임의적이거나 해석이 용이하다는 등의 이유로 표준화 자료 (즉, 상관행렬)를 분석에 사용하는 관행이 있으나 상관행렬은 분산에 관한 내용을 포함하고 있지 않아 정보의 손실이 있다. 특히, $\mathrm{M}$ 법(최우법)이나 GLS법(일반최소제곱법) 은 척도불변성(scal e invari ance) 이라는 바람직한 특성이 있으므로 구성개념간의 관계를 측정단위에 구애받지 않고 분석할 수 있게 해준다( Bollen, 1989). 상관행렬이 분석될 경우에는 다음과 같은 문제점이 발생할 수 있다(Cudeck 1989; J reskog and S rbom 1988; J reskog et al. 1999).

(1) 등식제약 등이 부여될 경우 분석될 모델이 수정된다.

(2) 부정확한 $\chi^{2}$ 값과 적합도 측도(measure) 가 산출된다.

(3) 부정확한 표준오차가 산출된다.

상관행렬로 분석할 경우에 발생하는 문제와 관련한 보다 상세한 사항은 “ LI SREL 8: New 
St at i stical Feat ure ( J r reskog et al . 1999) '의 pp. 213-218에서 자세히 설명하고 있다.

\section{8 표본크기의 확인과 분석에 선택된 변수 지정의 중요성}

$\mathrm{DA}$ 라인에서 가령, $\mathrm{NI}=5$ 라는 명령어는 '입력될 변수'가 5 개라는 것을 의미하므로, 분석되는 변수의 개수(個數) 와는 관계없이' 입력되는 모든 변수의 수를 밝히기 위한 명령어이다. 입력변수가 모두 분석에 사용될 때에는 입력변수의 수와 분석변수의 수가 일치한다. 그러나 일부의 변수만을 분석에서 사용하거나 입력될 순서를 바꾸어야 할 경우에는 SE라인을 사용해야 한다. SE라인에 의해 변수의 선택과 순서 바꾸기를 실시하고자 할 때, 만약 일부의 변수만을 선택해야 하는 경우에는 반드시 / 기호를 끝 부분에 두어야 한다. 이 / 기호는 선택에서 제외된 나머지 변수는 분석에 포함시키지 않고 버리겠다는 의미이다. 선택된 변수만을 대상으로, 순서 바꾸기가 지정된 경우에는 순서를 바꾼 상태에서, 분석될 행렬이 계산된다. 변수의 선택과 순서 바꾸기는 SE라인에서 변수명(變數名) 을 사용하여 지정하거나, 단위번호 (즉, data file에 있어서의 변수의 순서대로 $1,2,3 \ldots$ 등의 번호가 부여됨) 를 사용하여 지정한다. 그리고 입력자료가 공분산행렬, 상관행렬 등의 형태로 요약되어 있는 경우에는 분석될 자료의 표본크기(sample si ze) 를 반드시 DA라인에서 밝혀야 한다. 표본크기의 지정을 빠뜨리면 프로그램의 실행이 중단된다. 원자료를 외부(外部) 파일로부터 읽어들일 때에는 표본크기를 지정하지 않고 초기치 상태로 두어도 프로그램이 알아서 계산해 준다. 표본크기의 확인은 자료를 제대로 읽어들였는지를 확인할 수 있는 한 방법이 되기도 하므로 반드시 확인해야 한다. 가능하면 원자료는 외부파일로부터 읽어들이는 것이 자료상의 오류를 발견하는데 유리하다.

\section{9 전반적인 적합도에 의한 모델의 적합도 검정}

구조방정식모델에 있어서 모델의 적합도를 결정하는 것은 다변량분석법에 있어서처럼 단순하지가 않다. 다변량분석법에 있어서는 거의 모든 경우 변수들이 오차 없이 측정되는 것으로 간주하며 분포가 알려진 통계적 검정법을 적용하고 있다. 그러나 구조방정식모델에 있어서는 주어진 표본자료로 모델의 적합도를 검정할 수 있는 유일한 통계적 적합도 검정법은 없으며 다양한 적합도 기준들이 존재한다. 엄밀히 말하면, $\chi^{2}$ 검정을 제외하고는 어떠한 적합도 기준도 관련된 통계적 검정방법이 개발되어 있지 않다고 볼 수 있다.

따라서, 대부분의 적합도 기준은 그 값의 범위가 $\mathrm{O}$ (無적합도)에서 1 (완벽한 적합도)로 구성되어 있지만 어느 정도가 수용할 수 있는 적합도 수준인지는 주관적으로 평가해야 한다. 연구자들 가운데는 적합도의 값을 0.90 이상으로 제안하는 연구자도 있다(Bal dwin 1989; Bentler and Bonett 1980). 적합도가 0.95 이상이면 매우 양호한 것으로 간주되고 있다. 예외적으로 $\mathrm{AlC}$ (아카이케 정보량기준) 와 RMR은 작을수록 적합도가 양호한 것으로 보아야 한다. 주요 적합도 기준별로 수용 가능한 수준을 요약하면 <표 3>과 같다.

1) 구조방정식모델의 관점에서 보면, "변수들이 오차 없이 측정된다고 가정하는 것"은 잠재변수와 관측 변수를 구분 없이 동일시하는 것과 같다. 따라서 한 구성개념에 대해 복수의 지표를 도입할 수 없 게된다. 
<표 3> 주요 적합도 기준별 수용 가능 수준

\begin{tabular}{|c|c|c|}
\hline 적합도기 준 & 수용가능한 수준 & 설 명 \\
\hline$\chi^{2}$ (Chi - squar e) & $\chi^{2}$ 통계표의 임계치 & 계산된 $\chi^{2}$ 값과 임계치를 비교 \\
\hline GFI ( Goodness- of - $\mathrm{fi}$ t ) & O( 무적합) 1(완벽한 적합도) & 0. 900이상이면 적합도 양호 \\
\hline AGFI ( Adj ust ed GFI ) & O( 무적합) 1( 완벽한 적합도) & 0. 900이상이면 적합도 양호 \\
\hline $\begin{array}{l}\text { RMR( Root - mean squar e } \\
\text { r esi dual ) }\end{array}$ & 조사자가 수준을 결정 & SUM 와 S의 근사성을 나타냄 \\
\hline $\begin{array}{l}\text { RINEA( Root- mean- squar e } \\
\text { er r or of appr oxi mat i on) }\end{array}$ & $\mid<0.05$ & 0. 05미만이면 적합도 양호 \\
\hline TLI ( Tucker- Lewi s i ndex) & O( 무적합) 1(완벽한 적합도) & 0. 900이상이면 적합도 양호 \\
\hline NFI ( Nor med fit i ndex) & O( 무적합) 1( 완벽한 적합도) & 0. 900이상이면 적합도 양호 \\
\hline $\begin{array}{l}\text { PGFI ( Par si mony } \text { goodness } \\
\text { of } \mathrm{fit} \text { i ndex) }\end{array}$ & ( 무적합) 1( 완벽한 적합도) & $\begin{array}{l}\text { 대체모델의 값을 비교( 클수록 } \\
\text { 적합도 양호) }\end{array}$ \\
\hline \begin{tabular}{|l} 
Al C( Akai ka i nf or mat i on \\
cri t er i on)
\end{tabular} & 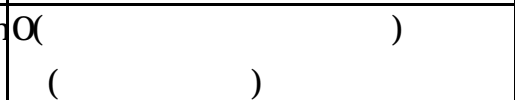 & $\begin{array}{l}\text { 대체모델의 값을 비교(작을수록 } \\
\text { 적합도 양호) }\end{array}$ \\
\hline
\end{tabular}

자료원: Schumacker and Lomax(1996 p. 112) 를 참고하여 작성함.

\section{10 결과 해석 및 보고 시의 유의사항}

출력에서 비표준화 해( unst andardi zed sol uti on) 와 아울러, OU라인에서 SS와 SC를 지정한 경우에는, 표준화 해( SS, standardized sol ution)와 완전표준화 해( SC, compl et ely st andardi zed sol uti on)가 결과에서 출력되는데 이 가운데서 표준화 해는 관측변수( $x$ 와 $\mathrm{y})$ 는 원래의 측정단위 그대로 두고 잠재변수 $(\xi$ 와 $\eta$ )만 분산이 1 이 되도록 표준화 시켜 얻은 해이며, 완전표준화 해는 관측변수는 물론 잠재변수도 분산이 1이 되도록 표준화시켜 얻은 해이다. 단, 잠재변수와 관측변수의 기대치는 기본적 가정에 의해 이미 $\mathrm{O}$ (영)으로 설정되어 있으므로 표준화 과정에서는 언급을 생략하고 있다.

그리고 표준화 해(SS)에서는 오차분산 $\sigma_{\varepsilon}$ 과 $\sigma_{\sigma}$ )에 대한 출력이 생략되어 있으나 비표준화 해와 동일하므로 비표준화 해의 해당란에서 읽으면 된다.

LISREL의 모수 추정치에 관한 출력 가운데서 LI SREL ESTI MATES라는 항목으로 출력되는 것이 비표준화 해이다. (초기치는 $\mathrm{M}$ 법에 의한 최우추정치임). 인과계수의 크기를 판정하고자 할 때 그 크기는 원인변수의 분산과 결과변수의 분산을 고려하여 판단해야 하므로 단순히 비표준화 해의 절대치를 비교해서는 곤란하다. 환언하면, 원인변수의 분산과 결과변수간의 분산의 비가 동일한 경우에 한해 비표준화 해를 이용한 인과계수의 절대적 크기의 비교가 가능하다. 따라서 인과계수의 크기를 비교할 수 있도록 LI SREL에서는, 앞에서 이미 언급한 것처럼, 두 가지의 표준화 해를 제공하고 있다. 이들 두 표준화 해에 대해 구체적으로 행렬과 연관시켜 설명하면 표준화 해(SS)에 있어서는 $\mathrm{B}, \Gamma, \Phi$ 및 $\Psi$ 의 계수만 표준화되며 $\Lambda_{x}$ 및 $\Lambda_{y}$ 는 비표준화 해와 비교할 때 수치상의 변화는 있지만 표준화되어 있지 않다. 완전표준화 해( SC)에 와서야 비로소 잠재변수와 관측변수 간의 
관계를 기술하고 있는 $\Lambda_{x}$ 와 $\Lambda_{y}$ 의 계수도 표준화된다.

표준화 해(SS)에서는 $\Phi(\mathrm{PH})$ 는 별도로 출력되지 않는다. 'CORRELATI ON MATRIX OF ETA AND $\mathrm{KSI}$ '란에서 ' KSI ( $\xi$ ) 간의 상관' 에 해당하는 곳을 읽으면 된다. 이 란은 잠재변수간의 상관을 계산해 놓은 것이다. 그리고 $\Theta_{\varepsilon}(\mathrm{TE})$ 과 $\Theta_{\sigma}(\mathrm{TD})$ 는 출력이 생략되어 있지만 이 둘은 비표준화 해의 것과 동일하므로 비표준화 해를 참조하면 된다. 표준화 해(SS)에서는 각 $\xi$ 를 독립변수로 하고 각 $\eta$ 를 종속변수로 하여 회귀분석을 실시한 결과가 'REGRESSI ON MATRI X ETA ON KSI (STANDARDI ZED) '라는 항목으로 출력된다. $\xi$ 가 하나 뿐인 경우에는 표준화 단순회귀계수에 해당하지만 $\xi$ 가 다수인 경우에는 표준화 편회귀계수가 된다.

완전표준화 해( $\mathrm{SC}$ )에서도 $\Phi$ 는 출력되지 않으므로 - CORRELATI ON MATRIX OF ETA AND $\mathrm{KSI}$ '란에서 읽으면 된다. 나머지 행렬에 대한 완전표준화 해의 출력은 제공된다. 통상, 모수의 유의성 검정은 비표준화 해를 대상으로 실시한 결과가 출력으로 제공된다. 하지만, 참조변수를 지정하지 않아 잠재변수를 표준화하여 해가 구해지는 경우에는 표준화 해에 대한 유의성 검정이 이루어진다(예컨대, 조 1999 p. 169).

연구 결과를 보고할 때 유의할 사항을 언급하면, 통상적으로는 비표준화 해와 표준화 해를 함께 제시하는 것이 좋을 것으로 보며, 아울러 다른 연구자가 참조할 수 있도록 '분석된 행렬'을 소수점 3자리까지 보고서에서 제시하는 것이 바람직하다. 소수점 2자리까지 제시한 경우 드물게 역행렬이 구해지지 않는 경우가 있기 때문이다.

\section{LI SREL에 있어서의 모수 유의성 검정상의 문제점}

LI SREL에서는 각 모수 (parameter)에 대한 유의성 검정에 $\mathrm{t}$ 검정을 적용하지만, 통상 표본크기가 100 이상이므로 이 유의성 검정에 적용하기 위해 각 모수별로 이론적으로 추정된 검정통계량의 표본추출분포( sampling distribution)는 $\mathrm{t}$ 분포를 따르지만 대표본이므로 $\mathrm{z}$ 분포에 근사하게 된다. 따라서 임계치(critical value)는 z분포의 임계치를 대신 적용한다.

LI SREL의 일반형모델( general model) 은 네 개의 계수행렬 (즉, $\Lambda_{x}, \Lambda_{y}, \mathrm{~B}$ 및 $\Gamma$ ) 과 다섯 개의 공분산행렬 (즉, $\Phi, \Theta_{\varepsilon}, \Theta_{\sigma}, \Psi$ 및 $\Theta_{\sigma \varepsilon}$ )로 구성되어 있으며 이들 행렬에서 필요한 모수의 유의성 검정에 양측검정을 적용하는 관행이 일반화되어 있다. 하지만 연구자에 의해 제시된 연구가설을 반영하는 경로계수인 $\mathrm{B}$ 와 $\Gamma$ 는 연구가설이 영향력의 방향을 명시하지 않은 경우에는 양측검정을 적용해야 하지만, 정(+)의 영향 혹은 부(-) 의 영향이라고 영향력의 방향을 명시한 경우에는 단측검정을 적용해야 한다. LI SREL을 포함한 구조방정식모델 관련 서적이나 논문에서 왜 연구가설에 대해 양측검정만을 적용해야 하는지에 대한 타당한 근거는 어디서도 찾아볼 수 없다. 다음 두 가설에서 연구가설 $1(\mathrm{RH} 1)$ 과 같이 영향력의 방향이 명시되지 않은 경우에는 양측검정을 적용해야 하며, 연구가설 2( RH2) 와 같이 ‘정의 영향' 이라고 영향력의 방향이 명시된 경우에는 우측검정을 적용해야 한다. 
연구가설 1(RH1): 직무만족은 조직시민행동에 영향을 미친다.

연구가설 2(RH2): 직무만족은 조직시민행동에 정의 영향을 미친다.

위의 두 연구가설에서 연구가설 $1(\mathrm{RH} 1)$ 은 이론적 추론이나 광범위한 관찰에 근거하여 영향력의 방향을 명시하기 어려울 때 세워야 하는 연구가설이지만, 이론적 추론이나 광범위한 관찰에 근거하여 영향력의 방향을 '정의 영향' 이라고 명시할 수 있는 경우에는 연구가설 2(RH2) 와 같이 세우고 검정해야 한다.

요약하면, 연구가설을 표현하고 있는 $\mathrm{B}$ 와 $\Gamma$ 의 원소에 해당하는 모수는 연구가설의 내용에 따라 양측검정과 단측검정을 구별해 적용해야 하고, 나머지 계수행렬 $\left(\Lambda_{x}, \Lambda_{y}\right)$ 및 공분산행렬 $\left(\Phi, \Theta_{\varepsilon}, \Theta_{\sigma}, \Psi, \Theta_{\sigma \varepsilon}\right)$ 의 원소에서 유의성을 검정할 필요가 있는 모수는 양측검정을 적용해야 할 것으로 본다.

모수에 대한 유의성을 검정함에 있어서 $\mathrm{t}$ 값의 크기와 유의수준 $\mathrm{a}$ 간의 관계를 양측검정과 단측검정으로 구분하여 <표 4>에 요약해 놓았다.

<표 4> 모수에 대한 가설검정시의 $\mathrm{t}$ 값과 유의수준 $\mathrm{a}$ 간의 관계

\begin{tabular}{|l|l|l|}
\hline $\mathrm{t}$ 값의 절대치 & 양측검정시 & 좌측검정이나 우측검정시 \\
\hline $\mathrm{t} \mid>2.58$ & $\mathrm{a}=0.01$ 에서 유의 & $\mathrm{a}=0.005$ 에서 유의 \\
\hline $\mathrm{t} \mid>2.33$ & $\mathrm{a}=0.02$ 에서 유의 & $\mathrm{a}=0.01$ 에서 유의 \\
\hline $\mathrm{t} \mid>1.96$ & $\mathrm{a}=0.05$ 에서 유의 & $\mathrm{a}=0.025$ 에서 유의 \\
\hline $\mid \mathrm{t} \mathrm{|} \mathrm{>1.645}$ & $\mathrm{a}=0.10$ 에서 유의 & $\mathrm{a}=0.05$ 에서 유의 \\
\hline
\end{tabular}

자료원: 조(1999 p. 116)

예를 들어, $\mathrm{t}$ 값의 절대치(絶對値) 가 1.96 보다 크면 양측검정 시에는 "유의수준 $\mathrm{a}=0.05$ 에서 유의하다" 고 결론을 내려야 한다. 하지만 좌측검정 혹은 우측검정 시에는 " 유의수준 $a=0.025$ 에서 유의하다" 는 결론을 내려야 한다. 물론, 단측검정 시에는 $\mathrm{t}$ 값의 부호도 고려해야 하므로 우측검정 시에는 양의 부호이어야 하며 좌측검정 시에는 음의 부호이어야 한다. 일반적으로 많이 적용되는 유의수준은 $a=0.01$ 과 $a=0.05$ 이다. 검정 결과를 요약한 표에서 | t |를 사용하여 검정결과를 표현하는 경우에는 문제가 없으나, 유의수준 $\alpha$ 를 사용하여 검정 결과를 표현하는 경우에는 연구가설이 양측검정이냐 단측검정이냐에 따라 $\alpha$ 를 적절히 적용해야 한다. 왜냐하면, 양측검정의 $a / 2$ 가 단측검정의 $\mathrm{a}$ 에 해당되기 때문이다. 단, | t | 를 사용하여 검정결과를 요약해 표현한 경우를 드물게 접하는 경우가 있으나, 본문에서 검정 결과에 대한 해석을 해야 하는 경우에는 유의수준 $\alpha$ 로 번역해 표현하도록 해야 할 것이다. 


\section{LI SREL 의 유용성과 한계}

여러 학문분야 특히, 사회과학분야와 같이 기초이론의 확립이 아직 미흡한 영역에 있어서는 이론(theory), 가설(hypothesis) 혹은 명제(proposition)를 검정할 필요성이 존재한다. 특히, 다수의 개념간의 유기적 관계를 고려하면서 검정할 필요성이 생겨난다. LI SREL은 이러한 목적에 유용하게 적용할 수 있는 강력한 통계적 분석도구의 하나이다. LISREL을 분석도구로 활용하고 있는 기존의 많은 연구들이 이를 실증해 주고 있다고 할 수 있다.

LI SREL을 포함한 구조방정식모델 또는 공분산구조분석은, 개략적으로 말하면, 확인적 요인분석(confi r mat ory fact or anal ysis) 과 경로분석(path analysis)이라는 두 분석기법을 통합하면서 경로분석의 도시기법(圖示技法)의 장점을 살리고 있다. LI SREL의 최대 장점은 잠재변수모델(구조방정식)에 의해 잠재변수가 다른 잠재변수에 미치는 효과는 물론, 측정모델(측정방정식)에 의해 잠재변수가 관측변수에 미치는 효과도 분석할 수 있다는 점이다. 따라서 복잡한 이론적 구조를 갖는 모델이나 이론을 실증적으로 연구하고 분석하는 데 매우 유용한 기법의 하나이다.

\section{1 LI SREL의 유용성}

구체적으로 LI SREL은 다음과 같은 유용성을 지니고 있다.

첫째로, 통상적인 다변량분석법과는 달리 종속변수와 독립변수에 대해 측정오차를 포함시켜 다룰 수 있다. 기존의 다변량분석에서는 변수 자체의 측정오차를 고려하지 않고 “ 오차 없이 측정 가능하다" 는 가정을 묵시적으로 도입하고 있다(조 1999 p. 129).

둘째로, 직접 관찰할 수 없는 잠재변수(구성개념) 를 포함하는 모델을 구축할 수 있으며 각 잠재변수에 대해 하나 혹은 다수의 지표(관측변수)를 적용할 수 있다. 사회과학에서 다루는 개념은 추상적인 경우가 대부분이므로, 이 다수의 지표를 적용하여 측정 오차를 고려할 수 있다는 점이 기존의 다변량분석법에 대해 갖는 구조방정식모델의 두드러진 강점이 된다.

셋째, 이론이나 모델을 연립방정식으로 설정해 놓고 모수를 동시에 추정할 수 있으므로 복잡한 이론적 구조나 연구가설에 대한 분석이 가능하다. 특히, 하나 혹은 둘 이상의 매개변수를 동시에 고려하여 고찰할 수 있다는 점을 지적할 수 있다. 예컨대, 매개변수의 역할과 관련하여 " $\mathrm{RH} 1:$ 집단 $\mathrm{A}$ 에 있어서는 매개변수를 통한 간접효과는 존재하지만 직접효과는 존재하지 않는다. RH2: 집단 B에 있어서는 매개변수를 통한 간접효과는 존재하지 않지만 직접효과는 존재한다" 와 같은 연구가설(예컨대, Mbore and Lutz 2000)의 검정이 가능하다.

넷째, 쌍방향(雙方向) 인과관계, 순환적(循環的) 인과관계, 제약모수(制約母數) 의 도입 등 모델의 표현방법이 풍부하여 대체적 가설이나 모델 가운데서 어느 것이 우월한가를 검증하는데 적합하다. 예컨대, 쌍방향 인과관계와 관련하여 “개념 $\mathrm{A}\left(\eta_{1}\right)$ 는 개념 $\mathrm{B}\left(\boldsymbol{\eta}_{2}\right)$ 에 영향을 미치지만, 개념 $\mathrm{B}\left(\eta_{\mathrm{l}}\right)$ 는 개념 $\mathrm{A}\left(\eta_{\mathrm{l}}\right)$ 에 영향을 미치지 않는다" 와 같은 
연구가설(예컨대, Bagozzi 1980)의 검정을 동시에 실시할 수 있다. 다양한 의미의 등식제약(等式制約) 을 부여하여 모수의 값이나 상관구조 등이 동일한지 여부를 검정 가능하다.

다섯째, 동일한 자료를 이용하여 축적된 지식과 이론적 바탕 하에서 모델을 단계적으로 수정해 갈 수 있으므로 모델의 개량이 용이하다. 이 경우 $\mathrm{M}$ (수정지수)와 $\mathrm{t}$ 값이 유용한 수단이 된다.

여섯째, 인과관계모델을 구축하고자 할 때, 독립변수들의 효과를 제거한 상태에서 종속변수들의 오차항 $\zeta$ ) 간에 상관이 존재하는지를 검토할 수 있으므로, 종속변수(즉, 구성개념) 간에 존재하는 상관이 고유한 상관인지 아니면 의사상관(spurious correl ati on) 인지를 검정할 수 있는 방법론을 제공한다(조 1999 p. 202) .

끝으로, 종래의 다변량분석법에서 다루어 온 거의 대부분의 분석기법을 하위모델로 포괄하고 있다(조 1999 p. 38).

\section{2 LI SREL의 한계}

LISREL이 위에 제시한 바와 같이 유용성을 지닌 기법이기는 하지만 이를 적용하고자 하는 경우, 연구자는 다음 사항에 유의해야 한다. LI SREL이 이론적 근거와 축적된 지식에 입각하여 설정한 인과관계 모델이나 가설을 검증하는데 유용한 기법이지만, 이 기법 자체가 인과관계를 확립해 주는 것은 아니라는 점이다 (Mttal, 1993). 이 지적은 구조방정식모델에 공통적으로 해당되는 것이다. 왜냐하면, 인과관계는 적용된 통계적 분석기법과는 관계없이 이론적 추론(theoretical inference)이나 실질적 지식(substantive know edge)에 근거하여 연구자가 설정해야 하는 것이지 어떤 통계적 분석기법을 적용했다고 하여 확립되는 것이 아니기 때문이다.

따라서 이론과 실질적 지식에 입각하여 설정된 인과관계모델의 경우에 한해서만 LI SREL, $\mathrm{AMOS}, \mathrm{CALIS}$ 등을 적용한 인과관계의 검증이 정당화될 수 있다. 뿐만 아니라, 이미 지적한 것처럼, LISREL을 포함한 구조방정식모델에서는 기존의 다변량분석법과는 달리 동일한 자료를 사용하여 모델의 개정을 연구자의 재량에 의해 단계적으로 해 갈 수 있다. 그러나 이 경우에도 인과관계를 설정할 때처럼 이론적 근거나 실질적 지식에 입각하여 설명이 가능한 경우에 한해서만 모델을 개정하도록 해야 한다. 특히, 적합도를 높일 목적으로 불필요한 모수까지 개방함으로써 모델을 자의적으로 수정하는 것은 삼가야 한다(참조: Hoyle 1995 p. 33). 자유모수의 수가 증가할수록 모수에 대한 해( sol ution)의 안정성은 낮아진다는 점을 유의할 필요가 있다.

\section{5. 요약 및 결론}

지금까지 LISREL 적용상의 주요 유의 사항과 문제점 및 이의 유용성과 한계점에 대해 고찰하였다. 구체적으로는, 구성개념과 지표간의 관계 및 구성개념간의 관계, 좋은 참조변수 
지정의 중요성, $\chi^{2}$ 검정 적용상의 유의사항, 모델을 식별 가능하게 하기 위한 조치, 초기설정치 제공의 필요성 및 수용하기 어려운 추정치에 대한 사항, 모델 탐색시의 유의사항, 상관행렬 적용 시에 수반되는 문제점, 표본크기 확인과 분석에 선택된 변수 지정의 중요성, 전반적인 적합도에 의한 모델의 검정, 결과 해석 및 보고 시의 유의사항, LISREL에서 관련 모수의 유의성 검정에 양측검정만을 적용함에 따른 문제점 등에 대해 살펴보았다. 특히, 연구가설에 해당하는 $\mathrm{B}$ 와 $\Gamma$ 는 연구가설의 내용에 따라 양측검정과 단측검정을 적용해야 할 상황이 구별되어야 한다는 점이 지적되었다. 끝으로, LI SREL은 인과관계를 분석하기 위한 연구에 다양한 유용성을 지닌 기법이지만 인과관계는 이론적 추론이나 광범위한 관찰에 입각하여 연구자가 설정해야 하는 것이므로, 적용된 분석 기법 자체가 인과관계를 확립해 주는 것이 아니라는 점이 지적되었다. 
<참고문헌>

임종원 편저 (1996), 마케팅 조사 이렇게, 서울: 법문사.

조현철 (1999), LISREL에 의한 구조방정식모델, 서울: 석정.

· 유재원 (2000), 「인적판매상황에서 조직시민행동의 선행변수에 대한 연구 $\lrcorner$,

『경영연구』, 한양대학교 경영연구소, 91-122.

Anderson, J. C and D. W, Gerbing (1988), " Structural Equation Modeling in Practice: A Review and

Recommended Two-Step Approach," Psychological Bulletin, Vol. 103(3), 411-423.

Bagozzi, Richard P. (1980), "Performance and Satisfaction in an Industrial Sales Force: An Examination of Their Antecedents and Simultaneity," Journal of Marketing, 44 (Spring), 65-77.

Baldwin, B. (1989)," A Primer in the Use and Interpretation of Structural Equation

Models," Measurement and Evaluation in Counseling and Development, 22, 100-112.

Bentler, P. M. and D. G. Bonett (1980)," SignificanceTests and Goodness-of-Fit in the analysis of

Covariance Structure," Psychological Bulletin, 88. 588-606.

Bollen, K. A. (1989), Structural Equations with Latent Variables, New York: Wiley.

Cudeck, R. (1989), "Analysis of Correlation Matrix Using Covariance Structure Model" , Psychological Bulletin, 105, 317-327.

Freedman, D. (1986) “ As Others See Us: A Case Study in Path Analysis" Journal of Esucation Statistics, 12, 101-128.

Hayduk, Leslie A. (1987), Structural Equation Modeling with LISREL : Essentials and Advances, Baltimore, MD: Johns Hopkins University Press.

Hoyle, Rick H. (1995), Structural Equation Modeling: Concepts, Issues, and Applications, Thousand Oaks, CA: Sage.

James, L. R., S. A. Mulaik and J. M. Brett (1982), Causal Analysis: Assumption, Models and Data, Thousand Oaks, CA: Sage

Jöreskog, K. G. and D. Sörbom (1988), LISREL 7: A Guide to the Program and Application, Chicago: SPSS Inc.

Stephen du Toit, and Mathilda du Toit (1999), LISREL 8: New Statistical Features, Mooresville, IN: Scientific Software.

Lomax, R. G. (1992), Statistical Concepts : A Second Course for Education and the Behavioral Sciences, New York: Longman.

Long, J. S. (1983a), Confirmatory Factor Analysis, Thousand Oaks, CA: Sage. (1983b), Covariance Structure Models: An Introduction to LISREL, Thousand Oaks, CA: Sage.

Makridakis, Spyros, and Steven C. Wheelwright (1978), Forecasting: Methods and Applications, New York: Wiley.

Marsh, H. W and D. Grason (1995), Latent Variable Models of Multitrait-Multimethod Data. In Rick H. Hoyle (ed.), Structural Equation Modeling : Concept, Issue and Application, Sage, 177-198.

Mittal, B. (1993),“ Testing Consumers Behavior Theories : LISREL Is Not A Panacea,” in Advances in Consumer Research, 20, eds. McAlister and Rothschild, Provo, UT: Association for Consumer Research, 647-653.

Moore, Elizabeth S. and Richard J. Lutz (2000), Children, Advertising, and Product Experiences: A Multimethod Inquiry, Journal of Consumer Research, 27 (June), 31-48. 
Mulaik, S. A., L. R. James, J. V. Alstine, N. Bennett, S. Lind, and C. D. Stilwell (1989), “ Evaluation of Goodness-of-Fit Indices for Structural Equation Models," Psychological Bulletin, 105, 430-445.

Neter, John, William Wasserman, and Michael H. Kutner (1985), Applied Linear Statistical Models, Homewood, IL: Irwin.

Schumacker, R. E., and R. G. Lomax (1996), A Beginner's Guide to Structural Equation Modeling, Mahwah, NJ: Lawrence Erlbaum.

豊田秀樹 (1992), SASによる共分散構造分析, 東京大學出版會. 